\title{
Adherence to guidelines: A national audit of the management of acute upper gastrointestinal bleeding. The REASON registry
}

\author{
Yidan Lu MD ${ }^{1}$, Alan N Barkun MD MSc ${ }^{1,2}$, Myriam Martel $\mathrm{BSc}^{1}$; and the REASON investigators
}

\begin{abstract}
Y Lu, AN Barkun, M Martel; and the REASON investigators. Adherence to guidelines: A national audit of the management of acute upper gastrointestinal bleeding. The REASON registry. Can J Gastroenterol Hepatol 2014;28(9):495-501.
\end{abstract}

OBJECTIVES: To assess process of care in nonvariceal upper gastrointestinal bleeding (NVUGIB) using a national cohort, and to identify predictors of adherence to 'best practice' standards.

METHODS: Consecutive charts of patients hospitalized for acute upper gastrointestinal bleeding across 21 Canadian hospitals were reviewed. Data regarding initial presentation, endoscopic management and outcomes were collected. Results were compared with 'best practice' using established guidelines on NVUGIB. Adherence was quantified and independent predictors were evaluated using multivariable analysis.

RESULTS: Overall, 2020 patients (89.4\% NVUGIB, variceal in $10.6 \%$ ) were included (mean [ \pm SD] age $66.3 \pm 16.4$ years; $38.4 \%$ female). Endoscopy was performed in 1612 patients: 1533 with NVUGIB had endoscopic lesions (63.1\% ulcers; high-risk stigmata in $47.8 \%)$. Early endoscopy was performed in $65.6 \%$ and an assistant was present in $83.5 \%$. Only $64.5 \%$ of patients with high-risk stigmata received endoscopic hemostasis; $9.8 \%$ of patients exhibiting low-risk stigmata also did. Intravenous proton pump inhibitor was administered after endoscopic hemostasis in $95.7 \%$. Rebleeding and mortality rates were $10.5 \%$ and $9.4 \%$, respectively. Multivariable analysis revealed that low American Society of Anesthesiologists score patients had fewer assistants present during endoscopy (OR 0.63 [95\% CI 0.48 to 0.83 ), a hemoglobin level $<70 \mathrm{~g} / \mathrm{L}$ predicted inappropriate high-dose intravenous proton pump inhibitor use in patients with low-risk stigmata, and endoscopies performed during regular hours were associated with longer delays from presentation (OR 0.33 [95\% CI 0.24 to 0.47]).

CONCLUSION: There was variability between the process of care and 'best practice' in NVUGIB. Certain patient and situational characteristics may influence guideline adherence. Dissemination initiatives must identify and focus on such considerations to improve quality of care.

Key Words: Gastrointestinal hemorrhage; Guideline adherence; Peptic ulcer hemorrhage; Quality of health care

U pper gastrointestinal bleeding (UGIB) is associated with significant morbidity and mortality. The incidence of acute nonvariceal UGIB (NVUGIB) ranges from 50 to 150 cases per 100,000 adults per year (1), while mortality varies from $2.5 \%$ to $10 \%(1,2)$. A large bleeding registry from 1999 to 2002 (3) revealed significant practice variations in the management of NVUGIB across Canadian hospitals (4). Several consensus recommendations have since been developed, setting well-defined standards (5-7). However, wide practice variations among physicians continue to be reported (8). Such variability calls to assess the quality of care delivered in NVUGIB. The latter extends beyond the measurement of outcomes such as rebleeding and mortality,
L'adhérence aux lignes directrices : une analyse nationale de la prise en charge des hémorragies digestives hautes aiguës. Le registre REASON

OBJECTIFS : Évaluer le processus des soins chez les patients présentant
une hémorragies digestives hautes non variqueuses (HDHNV) au sein
d'une cohorte nationale et déterminer la conformité à la 'bonne pratique'.
MÉTHODOLOGIE : Une analyse de dossiers consécutifs de patients
hospitalisés en raison d'hémorragies digestives hautes aiguës au sein de
21 hôpitaux canadiens a été effectuée, incluant les données relatives à la
présentation initiale, au traitement endoscopique et aux résultats. La
conformité quant aux lignes directrices a été quantifiée et les prédicteurs
indépendants ont été évalués via une analyse multivariable. RÉSULTATS : Au total, 2020 patients (89,4 \% HDHNV, et 10,6 \% de

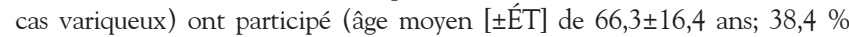
de sexe féminin). Une endoscopie a été exécutée chez 1612 patients : 1533 de ceux ayant une HDHNV avaient une lésion endoscopique (63,1\% des ulcères; $47,8 \%$ des stigmates à haut risque). Une endoscopie précoce a été effectuée chez $65,6 \%$ des patients, en présence d'un assistant dans $83,5 \%$ des cas. Seulement $64,5 \%$ des patients ayant des stigmates à haut risque ont reçu une hémostase endoscopique, de même que 9,8\% des patients présentant des stigmates à faible risque. Après l'hémostase endoscopique, des inhibiteurs de la pompe à proton par voie intraveineuse ont été administrés chez 95,7\% des patients. Les taux de récidive de l'hémorragie et de mortalité s'élevaient à $10,5 \%$ et $9,4 \%$, respectivement. L'analyse multivariable a révélé que moins d'assistants étaient présents pendant l'endoscopie chez les patients ayant un score faible selon l'American Society of Anesthesiologists (RC 0,63 [95 \% IC 0,48 à 0,83), tandis qu'un taux d'hémoglobine inférieur à $70 \mathrm{~g} / \mathrm{L}$ était prédictif de l'utilisation d'inhibiteurs de la pompe à protons intraveineux à haute dose chez les patients ayant des stigmates à faible risque, et que les endoscopies effectuées pendant les heures normales s'associaient à des délais plus longs suivant la présentation ( $\mathrm{RC} 0,33$ [95\% IC 0,24 à 0,47]).

CONCLUSION : On note une variabilité entre le processus des soins et les recommandations de 'bonne pratique' chez les patients avec une HDHNV. Certaines caractéristiques relatives aux patients ou à la situation clinique semblent influencer l'adhérence aux lignes directrices. Toute initiative de diffusion des lignes directrices doivent prendre en compte ces résultats afin d'améliorer la qualité des soins.

and includes the evaluation of the structure and delivery of care through process-based measures $(9,10)$. Optimally, the process of care should be consistent with evidence-based 'best practice' (8).

The Registry of patients undergoing Endoscopic and/or Acid Suppression therapy and an Outcome analysis for upper gastrointestinal bleediNg (REASON) recorded the 'real-life' hospital and physician practice managing acute UGIB across Canadian hospitals. The process of care was compared with 'best practice' recommendations available at the time, namely international NVUGIB consensus guidelines (5) published one year before the national cohort study. We present Canadian nationwide data regarding the structure, process and

Divisions of ${ }^{1}$ Gastroenterology; ${ }^{2}$ Epidemiology Biostatistics and Occupational Health, McGill University Health Centre, McGill University, Montreal,

Quebec

Correspondence: Dr Alan Barkun, Division of Gastroenterology, The McGill University Health Centre, Montreal General Hospital Site, 1650 Cedar Avenue,

Room D7-185, Montreal, Quebec H3G 1A4. Telephone 514-934-8233, fax 514-834-8575, e-mail alan.barkun@muhc.mcgill.ca

Received for publication May 16, 2014. Accepted June 9, 2014. 
outcomes of care as measures of quality of care (10) in light of 'best practice' guidelines and assess the impact of the latter.

\section{METHODS}

\section{REASON initiative and data collection}

A retrospective chart review of unselected hospitalized patients with a diagnosis of UGIB was performed in 21 Canadian hospitals. One hundred charts per institution were reviewed, starting from January 2004 until a total of 2000 cases was reached. Data collection was performed using an electronic system. Data were audited for the first 10 patients at each site, and randomly thereafter in 10\% to ensure standardization.

\section{Patient population}

All hospitalized patients at least 18 years of age with a primary or secondary discharge diagnosis of NVUGIB and variceal UGIB were identified using International Classification of Diseases, Ninth and 10th Revision (ICD-9 and ICD-10) codes via each hospital's electronic record database. Only hospitalized patients were included. Patients discharged from the emergency room or those transferred from another institution were excluded. Individuals already hospitalized for another reason, but who developed UGIB during their stay, were included. The performance of endoscopy was not an inclusion criterion.

\section{Study variables}

Structure and process of care: initial presentation and endoscopic management: Baseline data with patient demographics (age, sex, relevant medical history and medications) and institutional information (staffing and facility) were obtained. A description of the initial bleeding event was collected for all patients. The performance of endoscopy (if any), in addition to timing, endoscopic findings and hemostatic modality used (if any) were reported. The single most likely culprit lesion in the opinion of the endoscopist was recorded, although additional findings were also recorded if present. High-risk endoscopic stigmata (HRS) were defined as active bleeding with spurting or oozing, or findings of a nonbleeding visible vessel or adherent clot. Lowrisk stigmata (LRS) were comprised of pigmented spots and clean-based ulcers. Furthermore, data regarding pharmacotherapy, blood transfusions and Helicobacter pylori testing were also collected.

Information was retrieved for all patients presenting with acute UGIB (variceal and nonvariceal source) if they met the above inclusion criteria. However, for patients who were diagnosed with bleeding due to portal hypertension at endoscopy, only preprocedure data are presented and information collected after endoscopy is omitted.

Outcomes: Rebleeding, recourse to angiography and surgery, length of stay and mortality were reported. Rebleeding was defined as overt hematemesis; passage of fresh blood per rectum; fall in hemoglobin concentration $>20 \mathrm{~g} / \mathrm{L}$ within any $24 \mathrm{~h}$ period after the first $24 \mathrm{~h}$; shock (systolic blood pressure of $\leq 90 \mathrm{mmHg}$ or a heart rate of $\geq 110$ beats/min) in the presence of continuing melena; or fresh blood in the stomach and/or duodenum at repeat endoscopy when further bleeding was suspected $(3,11,12)$. All outcome data were collected for a 30-day period following the initial bleeding event.

Best practice: adherence to guidelines and its possible predictors: Adherence to guidelines was determined using the most recent guidelines available at the time of data collection (5), which featured 20 recommendations pertaining to the management of NVUGIB. Each recommendation was reviewed in light of available data from REASON, and adherence rates were calculated using ratios and percentages, except when data were insufficient or missing from the registry. Data were compared with a similar cross-sectional study preceding the publication of the guidelines (4).

For selected recommendations, possible independent predictors of guideline adherence were assessed, including the patient's age $(<60,60$ to 80 or $>80$ years of age), sex, pre-endoscopic Rockall score ( 0 to 2 , or $>2$ ) and Blatchford scores ( 0 to 2, 3 to 11 , or $>11$ ), American Society of Anesthesiologists (ASA) classification (1 to 2, 3, or 4 to 5$)$, presenting hemoglobin level $(<70 \mathrm{~g} / \mathrm{L})$ and time of endoscopy (regular hours defined as Monday to Friday from 08:00 to 17:00 versus after hours).

\section{Data analysis}

Categorical data were expressed as proportions and 95\% CIs, and continuous data as means \pm SD. Interquartile range $(I Q R)$ and median were also used when appropriate. Univariable analysis was performed using $\chi^{2}$ or Wilcoxon-rank testing. Independent predictors of guideline adherence were identified using the best fitting multivariable logistic regression models that were clinically relevant; $\mathrm{P}<0.05$ was considered to be statistically significant. All statistical analyses were performed using SAS version 9.2 (SAS Institute Inc, USA).

\section{Ethics}

Informed consent from individual patients was not deemed necessary because the study was considered to be an audit at all sites. The institutional review boards from all participating centres gave approval for the REASON data collection and analysis.

\section{RESULTS}

Structure of care: institutional and endoscopic facility data

Across the 21 hospitals, the mean number of endoscopists on staff was 11 per hospital (median nine; range three to 26). After-hours trained endoscopic support staff were available in 17 of 21 (81\%) hospitals, of which 13 of $17(76 \%)$ were available 24 h/day. Assistants were present to assist endoscopy in $83.5 \%$ of cases. Fewer than one-half (10 of $21[48 \%])$ of the hospitals had explicit written guidelines on intravenous proton pump inhibitor (IV PPI) use; a standardized critical care path for the management of patients with suspected UGIB existed in a similar proportion of institutions (11 of 21 [52\%]).

Clips were accessible in all hospitals, followed by injection (20 of 21 [95\%]); other devices included gold probe (17 of 21 [81\%]), argon plasma coagulation (15 of 21 [71\%]), heater probe (15 of 21 [71\%]), and bipolar or multipolar electrocoagulation (13 of 21 [62\%]).

\section{Study population}

Data from 2020 patients with UGIB were collected between January 2004 and May 2005. A total of 1805 (89.4\%) patients presented with NVUGIB and 215 (10.6\%) with variceal bleeding. The mean $( \pm \mathrm{SD})$ age was $66.3 \pm 16.4$ years, with a male predominance (1245 of 2020 [61.6\%]). Nearly one-fifth (356 of 2020 [17.6\%]) of all patients experienced the bleeding episode while already hospitalized for another reason. The mean Blatchford score was 9.1 \pm 4.1 (minimum $=0$; maximum $=23$ ), while the pre-endoscopic mean Rockall scores were $2.0 \pm 1.5$ (minimum $=0$; maximum $=7$ ). The overall ASA score distribution was $80.2 \%$ ASA score 1 to $3,19.8 \%$ ASA score 4 and 5 .

\section{Process of care}

Initial management: Twenty-two percent (448 of 2020) of patients underwent nasogastric tube lavage: $38.4 \%$ (172 of 448) revealed coffeeground material, 27.5\% (123 of 448) bright red blood and 4.0\% (18 of $448)$ bile. Only five of the $21(24 \%)$ hospitals routinely obtained nasogastric tube aspirates for the majority of their patients. The mean presenting hemoglobin level was $98.0 \pm 27.8 \mathrm{~g} / \mathrm{L}$. Sixty-nine percent of patients received a blood transfusion, at a median time of $8.7 \mathrm{~h} \mathrm{(IQR}$ $3.9 \mathrm{~h}$ to $24.0 \mathrm{~h}$ ) from presentation, with the vast majority $(74.9 \%)$ occurring in the first $24 \mathrm{~h}$. Among those transfused, $16.8 \%$ had an initial hemoglobin level $\leq 70 \mathrm{~g} / \mathrm{L}, 39.2 \%$ between $71 \mathrm{~g} / \mathrm{L}$ and $100 \mathrm{~g} / \mathrm{L}$ and $44.0 \%$ a level $>100 \mathrm{~g} / \mathrm{L}$.

Overall, $68.2 \%$ (1113 of 1632) of patients presenting with acute NVUGIB received pre-endoscopic IV PPIs. These were administered at high dose with an $80 \mathrm{mg}$ bolus, followed by $8 \mathrm{mg} / \mathrm{h}$ infusion in $54.5 \%$ (698 of 1281). Prokinetic use was not recorded.

Time to endoscopy: The median time to endoscopy was $17.7 \mathrm{~h}$ (IQR $6.1 \mathrm{~h}$ to $29.4 \mathrm{~h}$ ). Patients with suspected variceal bleeding underwent endoscopy significantly earlier than individuals with suspected nonvariceal bleeding, with a median time to endoscopy of $12.4 \mathrm{~h}$ (IQR $4.5 \mathrm{~h}$ to $25.0 \mathrm{~h}$ ) compared with $18.3 \mathrm{~h}$ (IQR $6.3 \mathrm{~h}$ to $30.0 \mathrm{~h}$ ) 

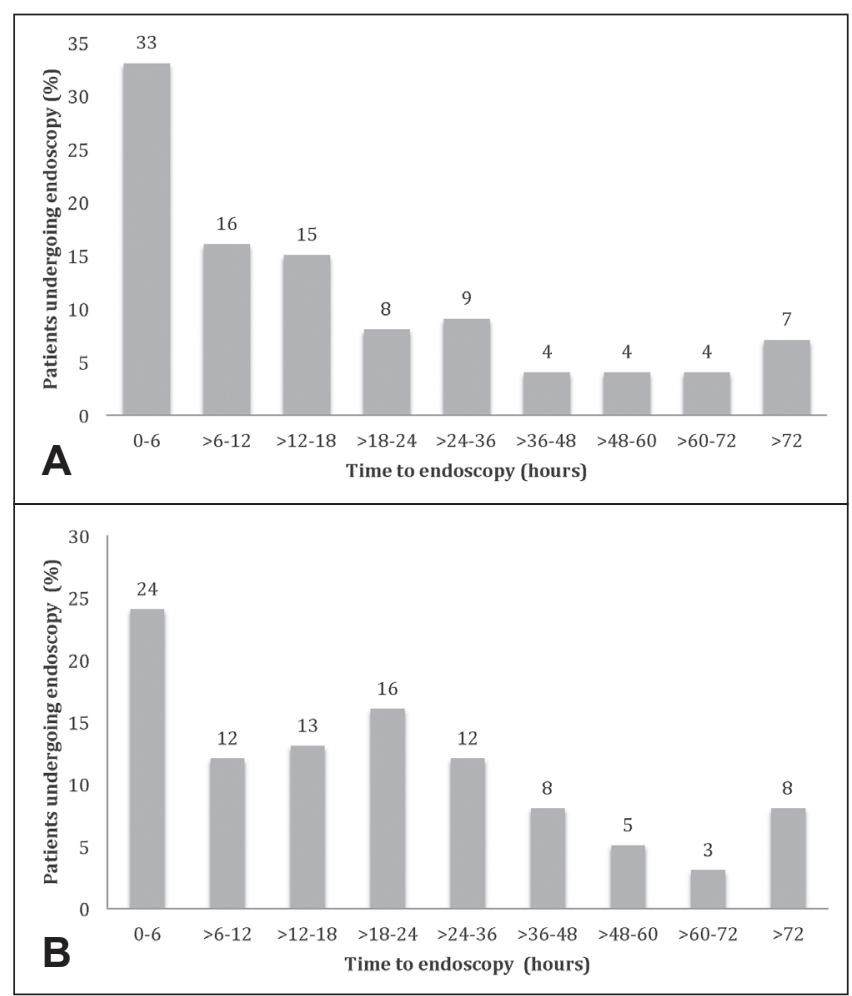

Figure 1) A Time to endoscopy for patients with suspected variceal bleeding. B Time to endoscopy for patients with suspected nonvariceal bleeding

for nonvariceal bleeding ( $\mathrm{P}=0.0038)$. Overall, $65.6 \%$ of patients underwent endoscopy within $24 \mathrm{~h}$. The distributions of time to endoscopy are shown in Figures 1A and 1B.

Endoscopic findings: Findings at endoscopy were recorded for both variceal and nonvariceal bleeding, although details pertaining to variceal bleeding will not be discussed further. A total of $89.4 \%$ (1805 of 2020) of patients were diagnosed with NVUGIB (Figure 2).

The etiologies of NVUGIB were distributed as follows: ulcers (967 of 1533 [63.1\%]), erosions (341 of 1533 [22.2\%]), esophagitis (313 of 1533 [20.4\%]), Mallory-Weiss tear (113 of 1533 [7.4\%]), malignancy (40 of 1533 [2.6\%]), Dieulafoy lesion (35 of 1533 [2.3\%]), gastric antral vascular ectasia syndrome (35 of 1533 [2.3\%]) and esophageal strictures (34 of 1533 [2.2\%]). More than one endoscopic diagnosis was possible for the same patient. Figure 3 illustrates the distribution of stigmata of recent hemorrhage in patients with nonvariceal bleeding, including ulcers and nonulcer lesions. While several diagnoses could be identified for the same patient, only the stigma from the lesion most likely to be the source of bleeding was recorded. Detailed documentation of endoscopic findings, more specifically, bleeding stigmata and description were unavailable in $30.1 \%$ (135 of 448) of cases. Excluding patients with no documentation of stigmata of recent bleeding, $71 \%$ had HRS.

Endoscopic therapy: Nearly two-thirds (64.5\%) of patients with HRS from both ulcer and nonulcer bleeding received endoscopic hemostasis. Moreover, $9.8 \%$ of patients LRS were also treated with endoscopy (Table 1). Epinephrine injection was used as monotherapy in $23.8 \%$ of patients with high-risk ulcers and $20.7 \%$ of all high-risk lesions. The most common endoscopic modalities used for the management of HRS lesions were injection monotherapy $(32.8 \%)$, combination therapy of injection and thermal (32.3\%), followed by thermal monotherapy $(14.5 \%)$ and clips (alone or in combination) (14.3\%). A routine (preplanned) second-look endoscopy was performed in 9.0\% (145 of 1612) of patients, while repeat endoscopy due to suspected rebleeding was performed in $56.7 \%$ (97 of 171).

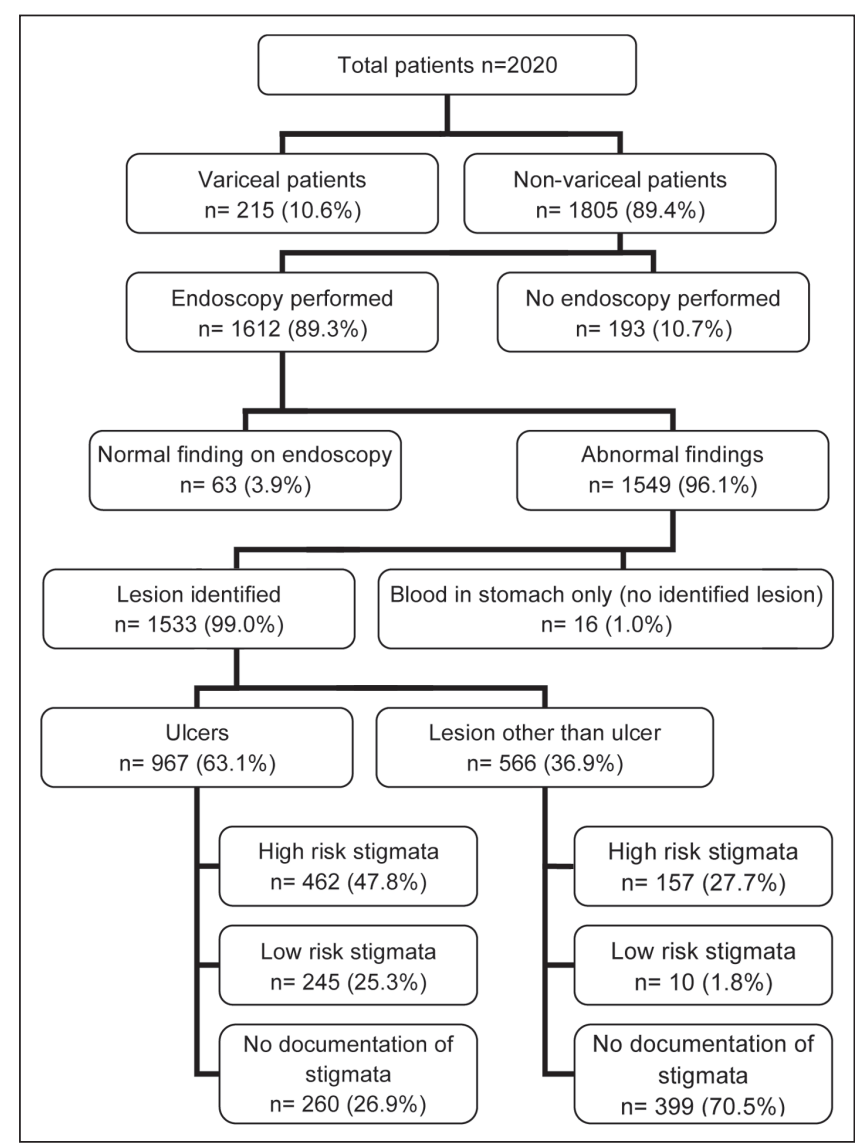

Figure 2) Distribution of patients presenting with acute upper gastrointestinal bleeding according to endoscopic findings

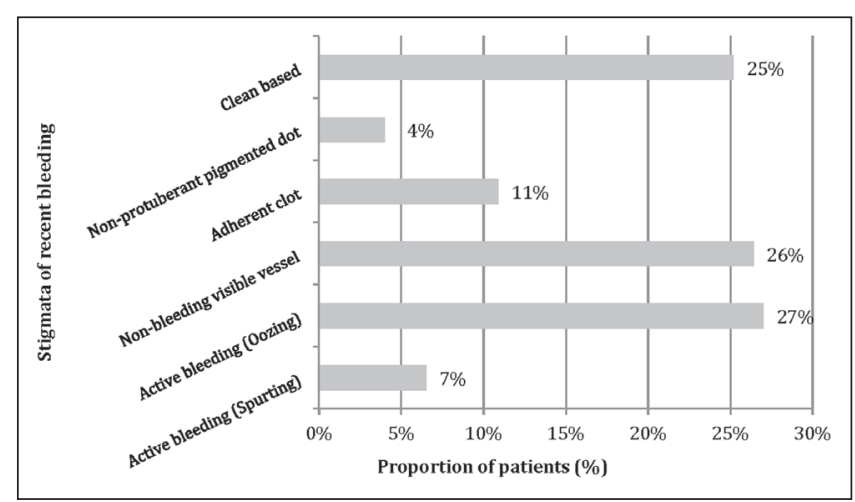

Figure 3) Distribution of stigmata of recent bleeding in nonvariceal upper gastrointestinal (ulcer and nonulcer lesions). Data representing stigmata from the lesion most likely to be the source of bleeding are shown

Pharmacotherapy: High-dose IV PPI ( $80 \mathrm{mg}$ bolus followed by continuous infusion) was administered to $95.7 \%$ of patients with HRS after successful endoscopic hemostasis. Overall, $91.5 \%$ of patients with LRS received high-dose IV PPI after endoscopy, irrespective of endoscopic therapy.

$\mathrm{H}$ pylori testing and treatment: $\mathrm{H}$ pylori status was available on presentation for $10.8 \%$ of patients ( $7.5 \%$ positive, $3.3 \%$ negative). Thirtysix percent of patients with NVUGIB were further tested for $H$ pylori during the course of their hospitalization, with eradication therapy initiated in $9.2 \%$ who tested positive. No data regarding the confirmation of eradication were available.

Outcomes: Rebleeding occurred in 10.5\% (190 of 1805) of patients, with an overall mortality rate of $9.4 \%$ (169 of 1805). A small proportion 
TABLE 1

Endoscopy and pharmacotherapy in ulcer and nonvariceal nonulcer upper gastrointestinal bleeding

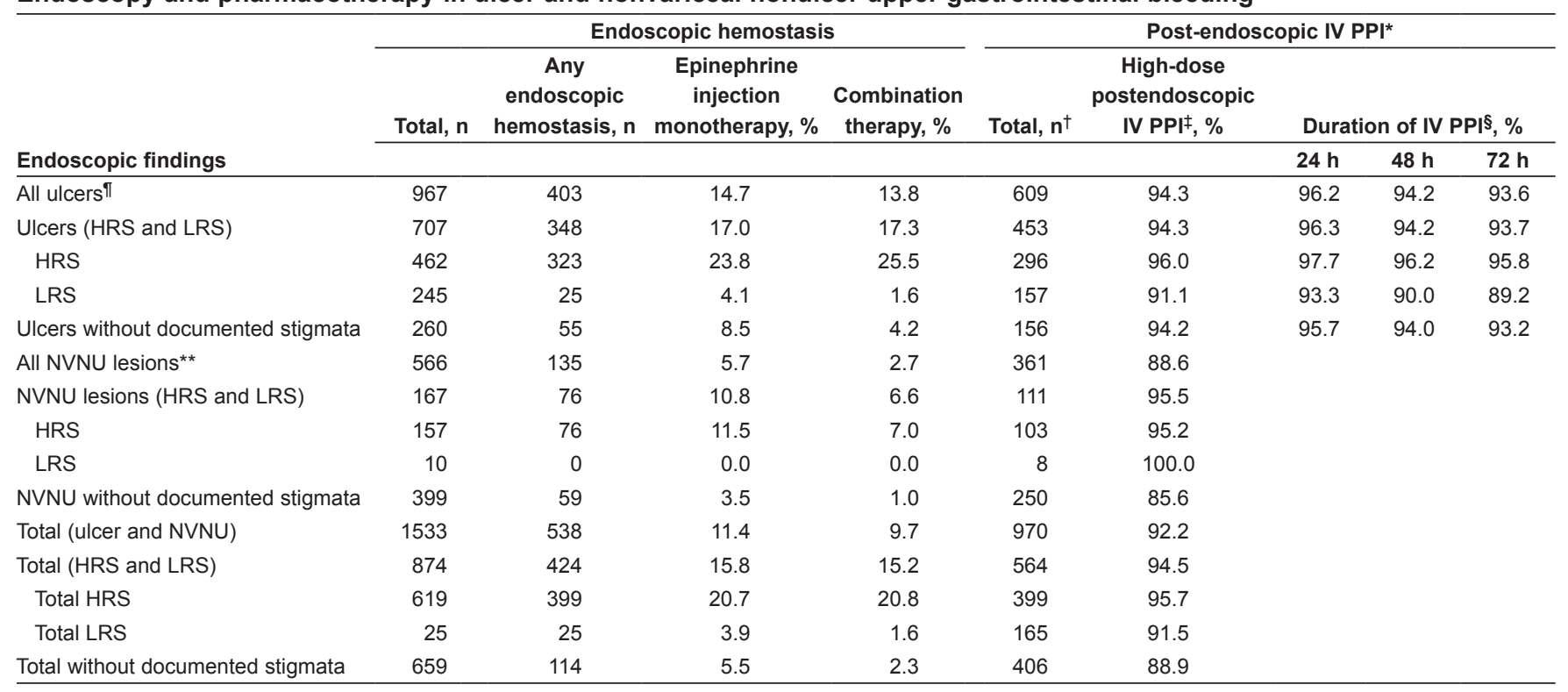

${ }^{*}$ Postendoscopic intravenous (IV) proton pump inhibitor (PPI) includes IV PPI therapy started after endoscopic therapy or continued if previous started pre-endoscopy; $\dagger$ Total number of patients who received postendoscopic PPI excluding those with missing information; $¥$ High-dose IV PPI defined as 80 mg IV bolus followed by 8 mg/h infusion started after endoscopic therapy or continued if started pre-endoscopy; §Data reported only for ulcer bleeding; $\Uparrow / n c l u d e s$ ulcers with high-risk stigmata (HRS), ulcers with low-risk stigmata (LRS) and ulcers without documentation of stigmata; **Includes nonvariceal nonulcer (NVNU) lesions with HRS, NVNU lesions with LRS and NVNU lesions without documentation of stigmata

of patients (47 of 1805 [2.5\%]) required surgery, while $1.2 \%$ (22 of 1805) required interventional radiology to control their bleeding. Of the patients who developed UGIB while hospitalized for another reason $(\mathrm{n}=356)$, rates of rebleeding, need for surgery and mortality were $14.4 \%, 1.4 \%$ and $21.9 \%$, respectively. Length of hospital stay was, on average, six days. Patients with NVUGIB who were admitted to the intensive care unit were discharged to the floor after a median of $5.8 \pm 10.1$ days.

Adherence to guidelines: The data from REASON were applicable to 13 of the 23 consensus recommendations (5) (Table 2). Comparing current adherence rates with data with a quantitative analysis of appropriateness in Canadian practice patterns performed before guidelines publication (4), higher adherence was noted in 67\% (eight of 12) of the recommendations (Figure 4). Two recommendations showed arithmetically decreased adherence rates (two of 12 [17\%]), namely the performance of early endoscopy within $24 \mathrm{~h}$ and endoscopic hemostatic therapy in HRS. Comparison was not performed for one recommendation due to the lack of preguideline values.

Predictors of adherence: Predictors of recommended use of endoscopic resources: Multivariable analysis revealed that the presence of qualified assistants during endoscopy occurred more frequently when endoscopy was performed during regular hours (OR 2.9 [95\% CI 2.21 to 3.81]). In contrast, patients with low ASA classification (1 to 2) more often underwent endoscopy without assistance from support staff (OR 0.63 [ $95 \%$ CI 0.48 to 0.83]) (Table 3). Furthermore, the targeted delay of $<24 \mathrm{~h}$ from presentation for early endoscopy was less likely to be met when an endoscopy was performed during regular hours (OR 0.33 [95\% CI 0.24 to 0.47]). High Blatchford scores of 3 to 11 predicted the performance of endoscopic therapy in patients with HRS (OR 1.67 [95\% CI 1.03 to 2.70]). No such predictors were identified to influence rates of endoscopic hemostasis in patients with LRS.

Predictors of recommended use of pharmacotherapy: The administration of high-dose IV PPI, which was not otherwise indicated in patients with LRS, was noted more frequently in patients with a presenting hemoglobin level $<70 \mathrm{~g} / \mathrm{L}$ (OR 6.84 [95\% CI 1.97 to 23.76]). This practice was less often encountered in patients who were on antithrombotic therapy (OR 0.39 [95\% CI 0.20 to 0.79]). No significant factors impacting on the use of high-dose acid suppressant were identified among patients with HRS. Significant predictors of adherence to the different recommendations and their respective ORs and 95\% CIs are listed in Table 3.

\section{DISCUSSION}

The assessment of quality of care in the management of patients with NVUGIB extends beyond the sole measurement of clinical outcomes, especially in view of high-level evidence now available to guide best practice. Process-based measures (9) were applied to REASON, a retrospective multicentre national registry of 2020 patients, to evaluate the quality of care in NVUGIB in Canada. Compared with data collected before the publication of consensus guidelines $(4,5)$, REASON demonstrates an improved adherence across over one-half of the recommendations, the median adherence remains low $(65.6 \%)$.

While the process of care is a dynamic exchange of events (8) and may preclude rigid application of guideline recommendations, adherence to guidelines remains an important surrogate of quality measurement. Such data for NVUGIB are scarce, with some reports suggesting marked differences in practice across countries (13) and suboptimal uptake of national guidelines (14). Predictors of adherence are poorly defined in the literature, even though some have been suggested as a result of a multifaceted randomized educational intervention for guideline dissemination (15). Inferential testing performed as part of the REASON data analysis shed some light on possible discrepancies between observed practice and existing guidelines. These are discussed below.

Areas where practice can be further improved include the implementation of a protocol to manage UGIB and access to adequate endoscopy assistance, even out-of-hours (recommendations 1 and 2). Interestingly, a low ASA class was associated with the absence of an assistant during endoscopy, independent of the time to endoscopy, suggesting a relaxing of standards for cases perceived to be less urgent or more stable.

Attention should be drawn to the use of appropriate resuscitation (recommendation 3) and transfusion thresholds because they impact 
TABLE 2

Recommendation statements with associated adherence rates after guideline publication

\begin{tabular}{|c|c|c|}
\hline & Recommendation statement (5) & Adherence, $\%(95 \% \mathrm{Cl})$ \\
\hline 1 & $\begin{array}{l}\text { Hospitals should develop institution-specific protocols for multidisciplinary management, which should include access to } \\
\text { an endoscopist with training in endoscopic hemostasis }\end{array}$ & $52(32.4-71.7)$ \\
\hline 2 & Support staff trained to assist in endoscopy should be available for urgent endoscopy & $83.5(59.4-92.9)$ \\
\hline 3 & Immediate evaluation and appropriate resuscitation are critical to proper management & $\mathrm{N} / \mathrm{A}(-)$ \\
\hline 4 & $\begin{array}{l}\text { In selected patients, the placement of a nasogastric tube can be considered because the findings may have prognostic } \\
\text { value }\end{array}$ & $22(20.4-24.0)$ \\
\hline $5 A^{*}$ & $\begin{array}{l}\text { Clinical (nonendoscopic) stratification of patients into low- and high-risk categories for rebleeding and mortality is } \\
\text { important for proper management. Available prognostic scales may be used to assist in decision making }\end{array}$ & $\mathrm{N} / \mathrm{A}(-)$ \\
\hline $5 B^{*}$ & $\begin{array}{l}\text { Early stratification of patients into low- and high-risk categories for rebleeding and mortality, based on clinical and } \\
\text { endoscopic criteria, is important for proper management. Available prognostic scales may be used to assist in } \\
\text { decision making }\end{array}$ & $\mathrm{N} / \mathrm{A}(-)$ \\
\hline $6^{*}$ & $\begin{array}{l}\text { Early endoscopy (within the first } 24 \mathrm{~h} \text { ) with risk classification by clinical and endoscopic criteria allows for safe and } \\
\text { prompt discharge of patients classified as low risk; improves patient outcomes for patients classified as high risk and } \\
\text { reduces resource use for patients classified as either low or high risk }\end{array}$ & $65.6(62.7-68.4)$ \\
\hline $7 \mathrm{~A}$ & $\begin{array}{l}\text { A finding of low-risk endoscopic stigmata (a clean-based ulcer or nonprotuberant pigmented dot in ulcer bed) is not an } \\
\text { indication for endoscopic hemostatic therapy }\end{array}$ & $90.2(85.3-93.0)$ \\
\hline $7 B^{*}$ & $\begin{array}{l}\text { Endoscopic hemostatic therapy is indicated for a patient with a clot in an ulcer bed, including targeted irrigation in an } \\
\text { attempt at dislodgment, with appropriate treatment of the underlying lesion }\end{array}$ & $\mathrm{N} / \mathrm{A}(-)$ \\
\hline $7 \mathrm{C}$ & $\begin{array}{l}\text { A finding of high-risk endoscopic stigmata (active bleeding, nonbleeding visible vessel and/or adherent clot) in an } \\
\text { indication for immediate endoscopic hemostatic therapy }\end{array}$ & $64.5(60.6-68.1)$ \\
\hline $8^{*}$ & No single solution for endoscopic injection therapy is superior to another for hemostasis & $\mathrm{N} / \mathrm{A}(-)$ \\
\hline 9 & No single method of endoscopic thermal coaptive therapy is superior to another & $\mathrm{N} / \mathrm{A}(-)$ \\
\hline $10^{*}$ & $\begin{array}{l}\text { Monotherapy, with injection or thermal coagulation, is an effective endoscopic hemostatic technique for high-risk } \\
\text { stigmata; however, the combination is superior to either treatment alone }\end{array}$ & $\mathrm{N} / \mathrm{A}(-)$ \\
\hline $11^{*}$ & The placement of clips is a promising endoscopic hemostatic therapy for high-risk stigmata & $14.3(11.2-18.1)$ \\
\hline $12^{\dagger}$ & Routine second-look endoscopy is not recommended & $91.0(89.5-92.3)$ \\
\hline 13 & In case of rebleeding, a second attempt at endoscopic therapy is generally recommended & $56.7(49.2-63.9)$ \\
\hline 14 & Surgical consultation should be sought for patients who have failed endoscopic therapy & $\mathrm{N} / \mathrm{A}(-)$ \\
\hline 15 & $\begin{array}{l}\mathrm{H}_{2} \text {-receptor antagonists are not recommended in the management of patients with acute upper gastrointestinal } \\
\text { bleeding }\end{array}$ & $95.1(94.1-96.0)$ \\
\hline 16 & $\begin{array}{l}\text { Somatostatin and octreotide are not recommended in the routine management of patients with acute nonvariceal upper } \\
\text { gastrointestinal bleeding }\end{array}$ & $100(100)$ \\
\hline $17^{\dagger}$ & $\begin{array}{l}\text { An intravenous bolus followed by continuous proton pump inhibitor infusion is effective in decreasing rebleeding in } \\
\text { patients who have undergone successful endoscopic therapy }\end{array}$ & $95.7(93.2-97.4)$ \\
\hline $18^{*}$ & In patients awaiting endoscopy, empirical therapy with a high-dose proton pump inhibitor should be considered & $54.4(51.8-57.2)$ \\
\hline 19 & Patients considered at low risk for rebleeding after endoscopy can be fed within $24 \mathrm{~h}$ & $\mathrm{~N} / \mathrm{A}(-)$ \\
\hline $20^{*}$ & $\begin{array}{l}\text { Patients with upper gastrointestinal bleeding should be tested for Helicobacter pylori and receive eradication therapy if } \\
\text { infection is present }\end{array}$ & $\mathrm{N} / \mathrm{A}(-)$ \\
\hline
\end{tabular}

${ }^{*}$ Recommendations that have been revised in the 2010 guidelines (7); ${ }^{\dagger}$ Statement updated from 2003 guidelines, but no change in the actual recommendation in the 2010 guidelines (7). N/A Not applicable

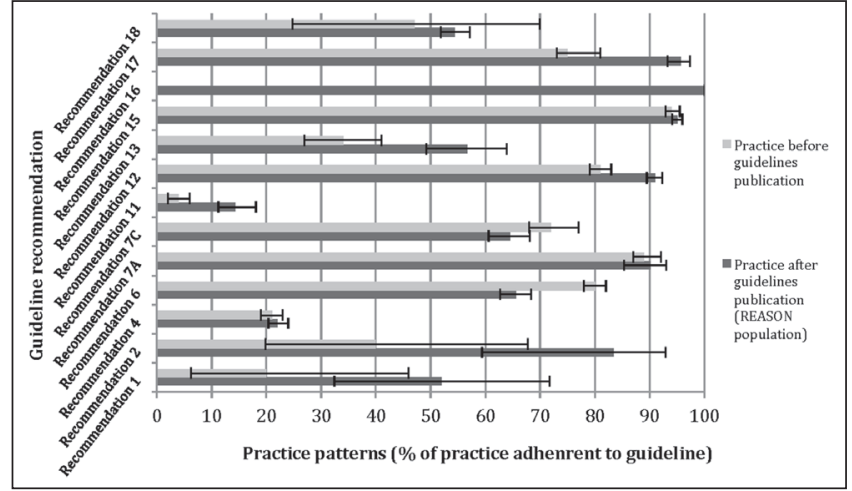

Figure 4) Adherence to recommendations comparing practice before and after guidelines publication. *Guidelines in which collected data were insufficient to assess adherence are not included; **Data before guidelines publication were not available for recommendation 16. REASON Registry of patients undergoing Endoscopic and/or Acid Suppression therapy and an Outcome analysis for upper gastrointestinal bleediNg

\section{TABLE 3}

Selected predictors of guideline adherence showing statistical significance

\begin{tabular}{|c|c|}
\hline $\begin{array}{l}\text { Recommendation with associated predictors of } \\
\text { adherence }\end{array}$ & OR $(95 \% \mathrm{Cl})$ \\
\hline \multicolumn{2}{|l|}{ Presence of assistants during endoscopy } \\
\hline American Society of Anesthesiologists class 1 to 2 & $0.63(0.48-0.83)$ \\
\hline Endoscopy performed during regular hours* & $2.9(2.21-3.81)$ \\
\hline \multicolumn{2}{|l|}{ Early endoscopy $<24 \mathrm{~h}$} \\
\hline Endoscopy performed during regular hours* & $0.33(0.24-0.47)$ \\
\hline \multicolumn{2}{|l|}{ Endoscopic therapy in patients with high-risk stigmata } \\
\hline Blatchford score 3 to 11 & $1.67(1.03-2.70)$ \\
\hline \multicolumn{2}{|c|}{ High-dose IV PPI administration in patients with low-risk stigmata } \\
\hline Presenting hemoglobin level $<70 \mathrm{~g} / \mathrm{L}$ & $6.84(1.97-23.76)$ \\
\hline Use of antithrombotics & $0.39(0.20-0.79)$ \\
\hline
\end{tabular}

${ }^{*}$ Regular hours endoscopy defined as Monday to Friday, 08:00 to 17:00 IV PPI Intravenous proton pump inhibitor 
rebleeding and survival rates in UGIB (16). The mean initial hemoglobin value in REASON was $98.0 \pm 27.8 \mathrm{~g} / \mathrm{L}$, comparable with RUGBE (3) and the recent randomized control trial by Villanueva et al (16). Over the first 24 h, only $16.8 \%$ of those who received a transfusion had a presenting hemoglobin level $\leq 70 \mathrm{~g} / \mathrm{L}$. Of note, this proportion includes all patients, regardless of associated cardiovascular morbidity and hemodynamic status, a group excluded, in large part, by inclusion criteria in the large multisite Spanish trial (16).

The administration of IV PPIs before endoscopy is common (54.4\%) even though their use is considered to be optional (recommendation 18) and no longer supported in recent United Kingdom guidelines (17) despite some clinical settings identified as possibly cost effective (18).

Overall, $65.6 \%$ of patients underwent early endoscopy within the recommended $24 \mathrm{~h}$ (recommendation 6). The point estimate is inferior to the $76 \%$ reported in RUGBE and European values ranging from $70 \%$ to $93 \%$ (13), while remaining superior to the $55 \%$ value reported in a true United Kingdom national bleeding audit (19). Additionally, longer delays ( $>24 \mathrm{~h}$ ) to endoscopy were associated with the endoscopies being performed during regular hours. This suggests that some patients have their endoscopy postponed until regular working hours, even if this results in delays exceeding $24 \mathrm{~h}$, perhaps because of limited out-of-hours support. Consistent with guidelines (20), patients with suspected variceal bleeding nevertheless underwent endoscopy significantly earlier, with a median of $12.4 \mathrm{~h}$ compared with $18.3 \mathrm{~h}$ for patients with NVUGIB ( $\mathrm{P}=0.0038)$.

At endoscopy, even though lesions were identified in the great majority of cases after one or multiple endoscopies, a substantial proportion of endoscopy reports ( $26.9 \%$ for ulcers) failed to document the severity of the stigmata of recent bleeding. Such a high value is unsettling because this information is needed for adequate risk stratification into high- and low-risk categories, which in turn is crucial for appropriate endoscopic and pharmacological management (recommendation 5). Failure to record endoscopic stigmata was even more frequent $(70.5 \%)$ among patients with nonvariceal, nonulcer bleeding, although both groups carry similar risk for unfavourable outcomes (21).

Patients exhibiting LRS do not require endoscopic therapy (recommendation 7A). Nonetheless, $9.8 \%$ of patients with LRS received endoscopic hemostasis in REASON, exceeding the $2.6 \%$ noted in an Italian prospective survey (22), although significantly inferior to a $24 \%$ endoscopic treatment rate for pigmented spots reported in the Clinical Outcomes Research Initiative database (23).

In contradistinction, although endoscopic hemostasis of lesions with HRS has clearly been shown to be associated with significant decreases in rebleeding, need for surgery and mortality (24) (recommendation 7C), adherence to such practice is suboptimal, with rates of $64.5 \%$ across all patients with NVUGIB and $69.9 \%$ among patients with ulcers. Reported rates of endoscopic treatment in high-risk patients in the literature range from $74 \%$ (3) to $85 \%(22,23)$. A French multicentre cohort proposes the lack of trained endoscopic assistance and out-of-hours endoscopy as possible factors for such practice (14).

The rate of injection monotherapy in REASON was $20.7 \%$. This practice is not consistent with guidelines that rather suggest the added value of combination therapy (recommendation 10); it is, nonetheless, improved compared with the preguidelines value of $39 \%$ (3). Furthermore, IV PPI administration following successful endoscopy reached $95.7 \%$, also superior to the previously reported $70.5 \%$ (recommendation 17). The only significant predictor of poor adherence in this regard was a low presenting hemoglobin level, which was associated with the use of high-dose IV PPI even in patients exhibiting LRS.

REASON did not record eradication rates, but reveals that $\mathrm{H}$ pylori testing (recommendation 20) was performed in only one-third of patients.

The REASON registry informs 'real life' practice in the management of UGIB, although it is limited by its retrospective nature. Our sampling excluded patients discharged from the emergency room, although it includes patients already hospitalized who develop a secondary diagnosis of UGIB, a subset at higher risk for complications (25). Missing data inherent to retrospective chart analyses somewhat undermine the accuracy of the calculated guideline adherence rates, although our values remain within ranges reported in the literature. Furthermore, the selected predictors of guideline adherence evaluated in our multivariate analysis may not be exhaustive and should be interpreted as exploratory because objective data regarding such predictors are scarce.

The above observations identify both areas of discrepant clinical care and some possible reasons for poor adherence that may guide future guideline dissemination initiatives. However, the impact of such educational efforts is often only modest. In fact, recent national data obtained from a 48-site cluster randomized clinical trial show that a multifaceted educational intervention over a 12 -month period to disseminate UGIB guidelines did not improve adherence (15). The issue of low guideline adherence is longstanding and complex involving attitude, knowledge, contextual and behavioural barriers $(26,27)$. Alternatively, the development of quality indicators using a list of more context-specific detailed clinical scenarios (28) may further help clinicians to reconcile 'best practice' in 'real-life' settings.

\section{CONCLUSION}

The process-based measures from the REASON registry reveal variable adherence to 'best practice' in NVUGIB in Canada. Proper endoscopic documentation, and adequate use of appropriate pharmacological and endoscopic therapy are key elements that clinicians should target to improve quality of care in NVUGIB. Both patient- and process-related factors may predict guideline adherence, or its lack. More precise characterization of such variables can help identify both clinician and patient subgroups for interventions, enhancing clinical management.

GRANT SUPPORT: The REASON study was funded by an at-armslength grant from Astra Zeneca Canada Inc for the data collection; they had no participation, nor input for the present article.

DISCLOSURES: The authors have no financial disclosures or conflicts of interest to declare.

AUTHOR CONTRIBUTIONS: Alan Barkun contributed to the conception, drafting and final approval of the work; Yidan Lu contributed to the conception, drafting and final approval of the work; Myriam Martel contributed to the conception, statistical analysis, drafting and final approval of the work; The REASON investigators contributed to the data collection of the REASON registry.

REASON INVESTIGATORS: David Armstrong, Alan Barkun, Raymond Bourdages, Marc Bradette, Ford Bursey, Naoki Chiba, Alan Cockeram, Gilbert Doummar, Carlo Fallone, James Gregor, Robert Hilsden, Gilles Jobin, Raymond Lahaie, Gaetano Morelli, Pardeep Nijhawan, Kenneth Render, Alaa Rostom, Gurpal Sandha, Thomas Sylwestrowicz, Sander Veldhuyzen van Zanten and Lawrence Worobetz.

\section{REFERENCES}

1. Hearnshaw SA, Logan RF, Lowe D, Travis SP, Murphy MF, Palmer KR. Use of endoscopy for management of acute upper gastrointestinal bleeding in the UK: Results of a nationwide audit. Gut 2010;59:1022-9.

2. Laine L, Yang H, Chang SC, Datto C. Trends for incidence of hospitalization and death due to GI complications in the United States from 2001 to 2009. Am J Gastroenterol 2012;107:1190-5.

3. Barkun A, Sabbah S, Enns R, et al. The Canadian Registry on Nonvariceal Upper Gastrointestinal Bleeding and Endoscopy (RUGBE): Endoscopic hemostasis and proton pump inhibition are associated with improved outcomes in a real-life setting. Am J Gastroenterol 2004;99:1238-46. 
4. Bensoussan K, Fallone CA, Barkun AN, Martel M. A sampling of Canadian practice in managing nonvariceal upper gastrointestinal bleeding before recent guideline publication: Is there room for improvement? Can J Gastroenterol 2005;19:487-95.

5. Barkun A, Bardou M, Marshall JK. Consensus recommendations for managing patients with nonvariceal upper gastrointestinal bleeding. Ann Intern Med 2003;139:843-57.

6. British Society of Gastroenterology Endoscopy Committee. Non-variceal upper gastrointestinal haemorrhage: Guidelines. Gut 2002;(51 Suppl 4):iv1-6.

7. Barkun AN, Bardou M, Kuipers EJ, et al. International consensus recommendations on the management of patients with nonvariceal upper gastrointestinal bleeding. Ann Intern Med 2010;152:101-13.

8. Esrailian E, Gralnek IM, Jensen D, et al. Evaluating the process of care in nonvariceal upper gastrointestinal haemorrhage: A survey of expert vs. non-expert gastroenterologists. Aliment Pharmacol Ther 2008;28:1199-208.

9. Palmer RH. Process-based measures of quality: The need for detailed clinical data in large health care databases. Ann Intern Med 1997;127(8 Pt 2):733-8.

10. Donabedian A. The quality of care. How can it be assessed? JAMA 1988;260:1743-8.

11. Lau JY, Sung JJ, Lee KK, et al. Effect of intravenous omeprazole on recurrent bleeding after endoscopic treatment of bleeding peptic ulcers. N Engl J Med 2000;343:310-6.

12. Daneshmend TK, Hawkey CJ, Langman MJ, Logan RF, Long RG, Walt RP. Omeprazole versus placebo for acute upper gastrointestinal bleeding: Randomised double blind controlled trial. BMJ 1992;304:143-7.

13. Lanas A, Aabakken L, Fonseca J, et al. Variability in the management of nonvariceal upper gastrointestinal bleeding in Europe: An observational study. Adv Ther 2012;29:1026-36.

14. Zeitoun JD, Rosa-Hezode I, Chryssostalis A, et al. Epidemiology and adherence to guidelines on the management of bleeding peptic ulcer: A prospective multicenter observational study in 1140 patients. Clin Res Hepatol Gastroenterol 2012;36:227-34.

15. Barkun AN, Bhat M, Armstrong D, et al. Effectiveness of disseminating consensus management recommendations for ulcer bleeding: A cluster randomized trial. CMAJ 2013;185:E156-66.

16. Villanueva C, Colomo A, Bosch A, et al. Transfusion strategies for acute upper gastrointestinal bleeding. N Engl J Med 2013;368:11-21.

17. National Institute for Health and Clinical Excellence (NICE). Gastrointestinal bleeding: The management of acute upper gastrointestinal bleeding 2012 [updated June 2012; cited 2013 December 12]. <http://guidance.nice.org.uk/CG141> (Accessed April 3, 2014).

18. Barkun AN. Should every patient with suspected upper GI bleeding receive a proton pump inhibitor while awaiting endoscopy? Gastrointest Endosc 2008;67:1064-6.

19. Jairath V, Kahan BC, Logan RF, et al. Mortality from acute upper gastrointestinal bleeding in the United kingdom: Does it display a "weekend effect"? Am J Gastroenterol 2011;106:1621-8.

20. Garcia-Tsao G, Sanyal AJ, Grace ND, Carey WD; Practice Guidelines Committee of American Association for Study of Liver Disease, Practice Parameters Committee of American College of Gastroenterology. Prevention and management of gastroesophageal varices and variceal hemorrhage in cirrhosis. Am J Gastroenterol 2007;102:2086-102.

21. Marmo R, Del Piano M, Rotondano G, et al. Mortality from nonulcer bleeding is similar to that of ulcer bleeding in high-risk patients with nonvariceal hemorrhage: A prospective database study in Italy. Gastrointest Endosc 2012;75:263-72, 72 e1.

22. Loperfido S, Baldo V, Piovesana E, et al. Changing trends in acute upper-GI bleeding: A population-based study. Gastrointest Endosc 2009;70:212-24.

23. Enestvedt BK, Gralnek IM, Mattek N, Lieberman DA, Eisen GM. Endoscopic therapy for peptic ulcer hemorrhage: Practice variations in a multi-center U.S. consortium. Dig Dis Sci 2010;55:2568-76.

24. Cook DJ, Guyatt GH, Salena BJ, Laine LA. Endoscopic therapy for acute nonvariceal upper gastrointestinal hemorrhage: A metaanalysis. Gastroenterology 1992;102:139-48.

25. Muller T, Barkun AN, Martel M. Non-variceal upper GI bleeding in patients already hospitalized for another condition. Am J Gastroenterol 2009;104:330-9.

26. Cabana MD, Rand CS, Powe NR, et al. Why don't physicians follow clinical practice guidelines? A framework for improvement. JAMA 1999;282:1458-65.

27. Hayes SM, Murray S, Dupuis M, Dawes M, Hawes IA, Barkun AN. Barriers to the implementation of practice guidelines in managing patients with nonvariceal upper gastrointestinal bleeding: A qualitative approach. Can J Gastroenterol 2010;24:289-96.

28. Kanwal F, Barkun A, Gralnek IM, et al. Measuring quality of care in patients with nonvariceal upper gastrointestinal hemorrhage: Development of an explicit quality indicator set. Am J Gastroenterol 2010;105:1710-8. 


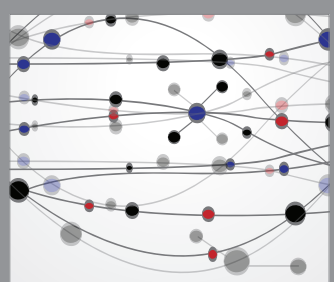

The Scientific World Journal
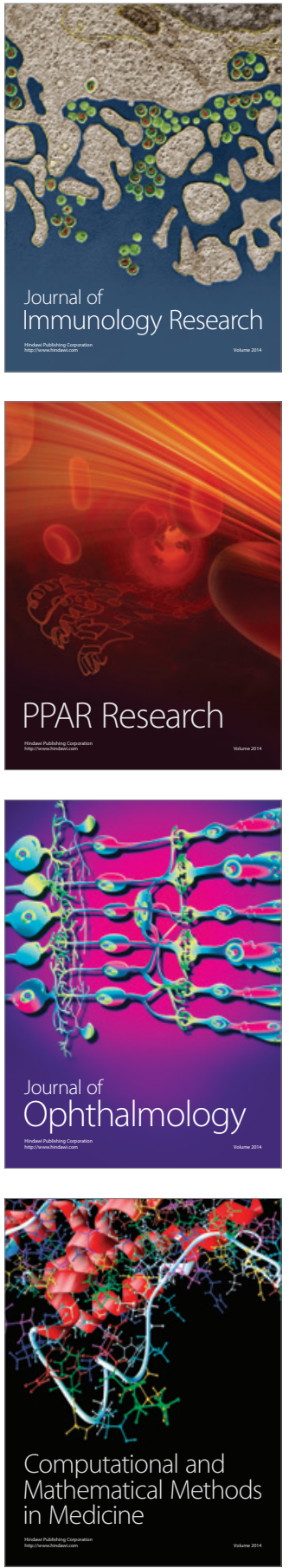

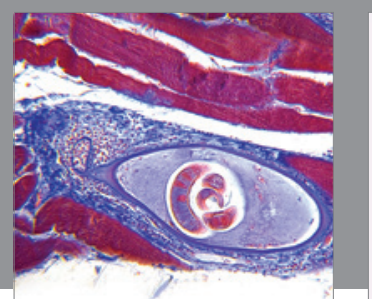

Gastroenterology Research and Practice

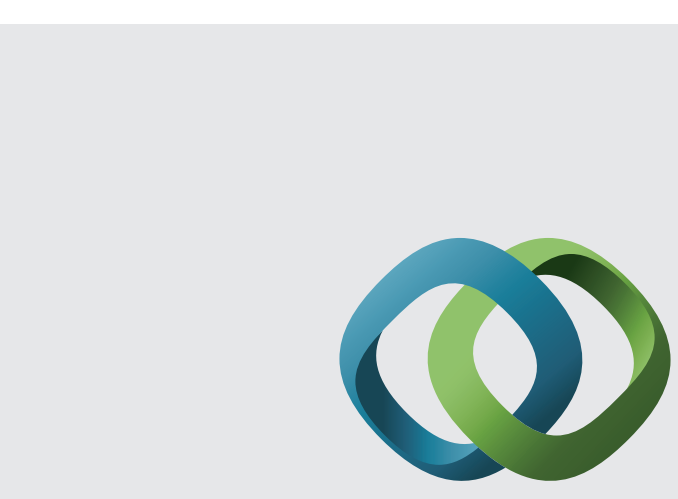

\section{Hindawi}

Submit your manuscripts at

http://www.hindawi.com
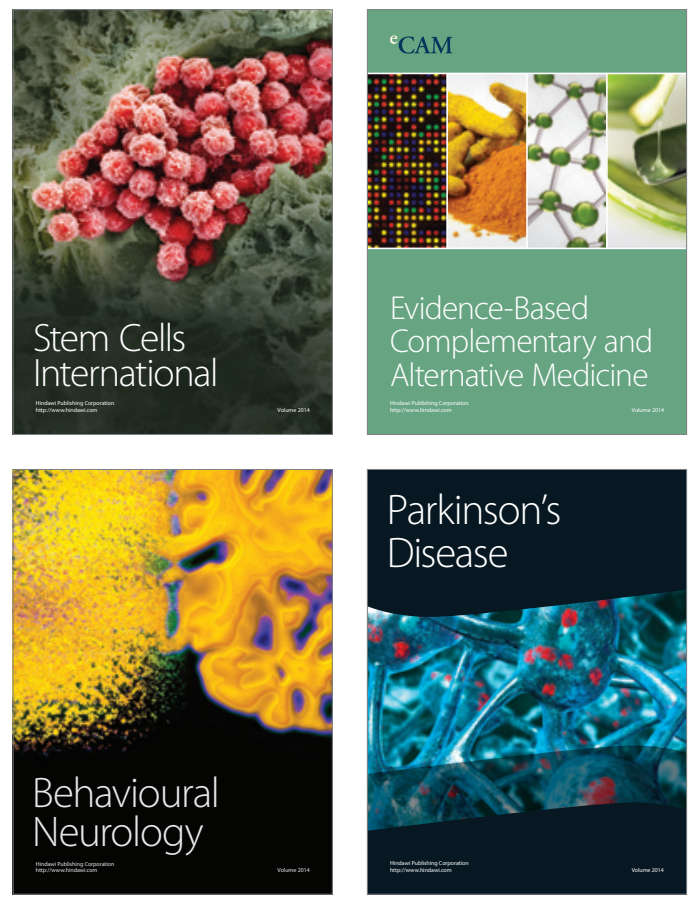
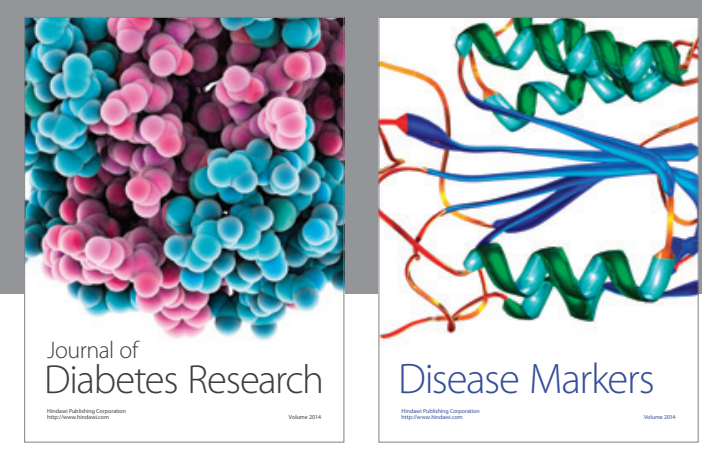

Disease Markers
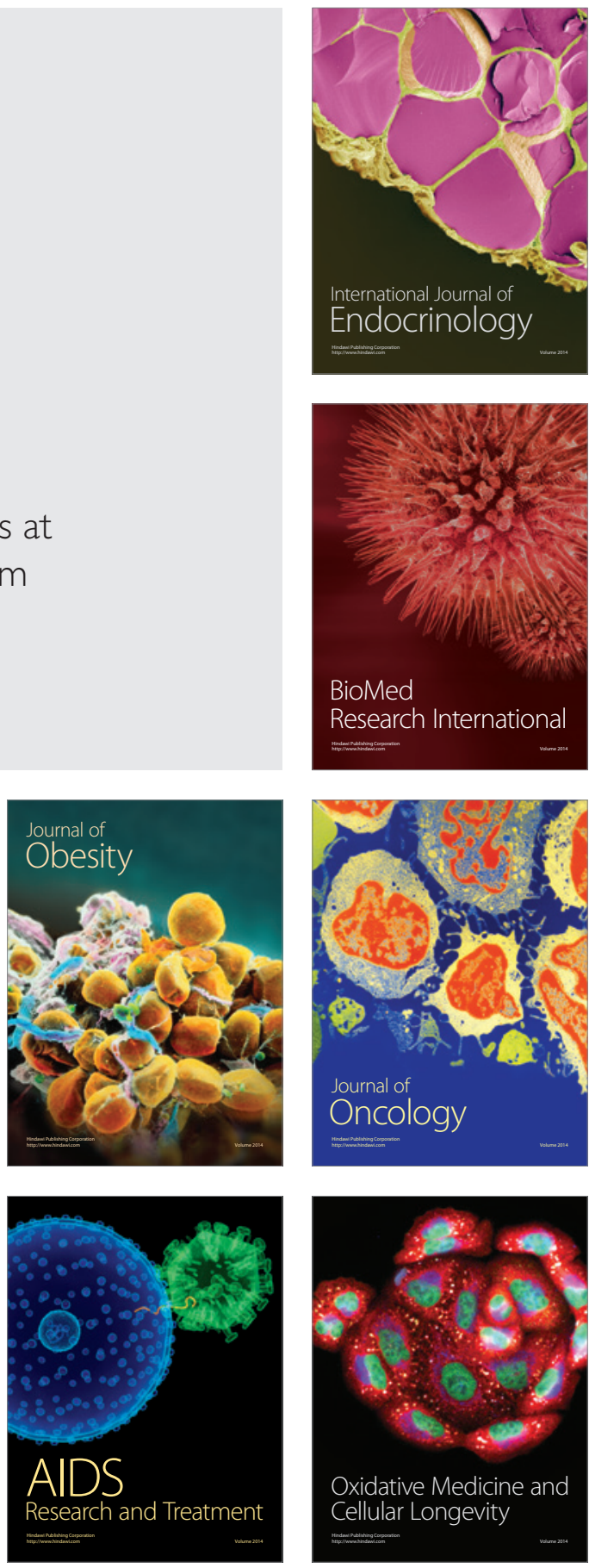